change in one or more external quantity; - $G_{0}^{-1} \Delta T$ is the change in $N$ due to the change in $T$ alone, where $G_{0}=-(\partial N /$ $\partial T)^{-1} \approx 0.3^{\circ} \mathrm{C}\left(\mathrm{Wm}^{-2}\right)^{-1}$ is the gain of the climate system without feedback; and $F \Delta T$ is the change in $N$ due to the change in the internal variables I through their dependence on $T$ (ref.2). When the equilibrium $\Delta T$ is reached in response to the forcing $\Delta Q, \Delta N=0$ and $\Delta T=G_{0} \Delta Q$ $(1-f)$, where $f$ is the sum of the individual feedbacks $f_{\mathrm{i}}=G_{\mathrm{o}} \partial N / \partial I_{\mathrm{i}} \mathrm{d} I / \mathrm{d} T$. Thus the feedback of a physical process $j$ depends on three quantities: (1) the zero-feedback gain of the climate system $G_{\circ},(2)$ the sensitivity of the net flux $N$ to the process as measured by $\partial N / \partial I_{i}$, and (3) the sensitivity of the process to the surface temperature as measured by $\mathrm{d} I / \mathrm{d} T$.

There are two possible feedbacks due to greenhouse-gas-induced changes in clouds. One is cloud-cover feedback, $f_{c}=$ $G_{0} \delta \mathrm{d} C / \mathrm{d} T$, where $C$ is cloud cover and $\delta$ $=\partial N / \partial C$ is the chnge in $N$ resulting from a change in $C$. The second is cloudoptical-depth feedback, $f_{t}=G_{0} \phi \mathrm{d} \tau / \mathrm{d} T$, where $\tau$ is the cloud optical depth and $\phi$ $=\partial N / \phi \tau$ is the change in $N$ resulting from a change in $\tau$. Several radiative transfer model studies (summarized in ref. 2 ) have shown that $\delta$ is negative for low and middle clouds, and is positive for high thin cirrus clouds. Other radiative transfer model studies (also summarized in ref. 2) have shown that $\phi$ is also negative for low and middle clouds, and is positive for high thin cirrus clouds. These results can be deduced from intuition. However, $\delta$ and $\phi$ are not the cloud-cover and cloudoptical/depth feedbacks. To determine the latter requires knowledge also of $\mathrm{dC} /$ $\mathrm{d} T$ and $\mathrm{d} \tau / \mathrm{d} t$, the changes in cloud cover and cloud optical depth which occur as a result of changes in surface temperature. In fact, it is the vertical integrals throughout the atmosphere of $\delta \mathrm{d} C / \mathrm{d} T$ and $\phi \mathrm{d} \tau / \mathrm{d} t$ which respectively determine the signs of the cloud-cover and cloud-opticaldepth feedbacks. It is these vertical integrals which are virtually impossible to estimate by intuition.

Consequently, it is not surprising that the cloud-cover feedback in recent general circulation model simulations of $\mathrm{CO}_{2}$ induced equilibrium climate change is positive as a result of a decrease in low and middle cloud cover $(\delta<0$ and $\mathrm{d} C / \mathrm{d} T<$ $0)$ and an increase in high cloud cover $(\delta$ $>0$ and $\mathrm{d} C / \mathrm{d} T>0)^{3-5}$. Similarly, it is also not surprising that the cloud optical depth feedback in a recent general circulation model simulation for a $2 \%$ increase in solar constant is positive due to an increase in the optical depth of high thin clouds $(\phi$ $>0$ and $\mathrm{d} \tau / \mathrm{d} T>0)^{6-x}$.

Michael E. Schlesinger

Department of Atmospheric Sciences and Climatic Research Institute,

Oregon State University,

Corvallis, Oregon 97331, USA

1. Maddox, J. Nature 334, 9 (1988)

2. Schlesinger, M.E. in The Potential Climatic Effects of Increasing Carbon Dioxide (eds MacCracken, M.C. \& Luther, F.M.) 280-319 (NTIS. Springfield, Virginia, 1985); in Physically-Based Modelling and Simulation of Climate and Climatic Change (ed. Schlesinger, M.E.) 653-736 and Climatic Change (ed.

3. Hansen st al. in Climate Processes and Climate Sensitivity (eds Hansen. J.E. \& Takahashi. T.) 130-163 (American Geophysical Union. Washington, DC. 1984).

Wetherald, R.T. \& Manabe, S. J. Atmos. Sci. 45, 1397-1415 (1988)

5. Schlesinger. M.E. in Contribution of Geophysics to Climate Change Studies, Proc. IUGG Symp. 15 (eds Berger. A. et al.) (Am. Geophys. Un.. in the press).

6. Roeckner, E., Schlese, U., Biercamp, J. \& Loewe, P. Nature 329, 138-140 (1987).

Schlesinger. M.E. Nature 333, 303 (1988)

Roeckner, E.et al. Nature 333, 303 (1988)

\title{
Unusual segregation of cystic fibrosis alleles
}

SIR-In a previous scientific correspondence', we described an unusual segregation of the cystic fibrosis (CF) allele to males. This was based on the observation of 60 French siblings of $\mathrm{CF}$ patients. Subsequently, two other small studies ${ }^{2.3}$ failed to confirm the initial claim.

We have now collected data from 21 European groups (including those in refs 2 and 3) and six North American groups, in which the CF status was analysed using the probes XV-2c and CS.7 (ref. 4), KM19 (ref 5), J3.11 (ref. 6) and MET (ref. 7). For each probe the alleles that are linked to the cystic fibrosis mutation were determined using at least one index case; no crossover families were used in this study.

In total, 1,003 unaffected siblings of $\mathrm{CF}$ probands were investigated. The unaffected siblings, have a male/female ratio of 1.018

Normal homozygotes, heterozygotes with the CF gene of paternal origin, and heterozygotes with the $\mathrm{CF}$ gene of maternal origin each represent approximately one third of the total number of unaffected children, as expected.

As shown in the table, of 349 normal homozygotes, 201 are girls and 148 are boys. This difference is statistically significant $\left(\chi^{2}=8.05, P<0.01\right)$. Of 654 heterozygotes there are 358 boys and 296 girls. This difference is also significant $\left(\chi^{2}=\right.$ 5.87, $P<0.02)$. For neither sons nor

\begin{tabular}{lccccr}
\hline & $\begin{array}{c}\text { Maternal CF } \\
\text { origin }\end{array}$ & $\begin{array}{c}\text { Heterozygous } \\
\text { Paternal CF } \\
\text { origin }\end{array}$ & Total & Normal & Total \\
\hline Boys & 178 & 180 & 358 & 148 & 506 \\
Girls & 150 & 146 & 296 & 201 & 497 \\
Total & 328 & 326 & 654 & 349 & 1003 \\
\hline
\end{tabular}

daughters who are heterozygotes, is there a statistically significant difference in the likelihood that the CF gene is of maternal or paternal origin.

For heterozygous offspring, there are more males than females, but this difference is not statistically significant whether the $\mathrm{CF}$ gene is inherited from the father $\left(\chi^{2}=3.55\right)$ or the mother (2.39). The sex ratio in heterozygotes inheriting the gene from the mother or the father is the same.

Although the statistical significance regarding preferential transmission of the $\mathrm{CF}$ gene from a parent to a child can be calculated in a variety of ways, the expanding data do not support our original conclusion' that the CF gene is preferentially transmitted from fathers to sons. But we conclude that there is a distortion in the expected sex ratio for normal homozygotes which results in an excess of girls, and a reciprocal difference in the sex ratio of heterozygotes which results in an excess of boys inheriting the $\mathrm{CF}$ gene from either their father or their mother.

The mechanism underlying the distortion in the sex ratio remains unclear. It could operate before fertilization, at the time of fertilization or through selective survival after fertilization. It will be important to determine if there is any distortion in the sex ratio of homozygous affected individuals at conception, although current postnatal detection does not provide evidence for a large excess of affected males. The data do not offer an immediate explanation for the high incidence of $\mathrm{CF}$ in the population but they could be of importance in this respect.

A. KitZis ET AL.*

Institut de Pathologie Moléculaire, CHU Cochin, 75014 Paris, France

"J.C. Chomel. A. Haliassos. L. Tesson. J.C. Kaplan. J. Feingold (Paris), G. Giraud. A. Labbe, B. Dastugue (Clermont-Ferrand). V. Dumur. J.P. Farriaux. P. Roussel (Lille). C. Ferrec (Brest). M. Vidaud. M. Goossens (Créteil). D. Bozon. M. Auvinet, V. Chambon. J. Andre (Lyon). W. Lissens, M. Bonduelle. I. Chambon. J. Andre (Lyon). W. Lissens, M. Bonduelle. I.
Liebaers, P. Cochaux. G. Vassart (Brussels). P. Willems (Antwerp). G. Duckworth-Raysiecki. B.S. Kerem. L.C. Tsui, P.N. Ray (Toronto). M. Krawczak. J. Schmidtke (Göttingen). G. Novelli, B. Dallapiccola (Rome and Urbino). G. Gasparni, P.F. Pignatti (Verona), M. Seia. M. Ferrari (Milan), M. Devoto. G. Romeo (Geneva) M. Schwarz M. Super. A. Ivinson A.P. Gead (Manester). L Meredith (Cardiff). A Curis (E.P. Read (Manchester). L.. Meredith (Cardirf). A. Curtis (Edinburgh), R. Williamson (London), A.L. Beaudet, G.L. Feldman. W. E. O'Brien (Houston). A.M. Bowcock. L.L. Cavalli-Sforza (Stanford), F. Gilbert (New-York). J. Braman (La Jolla), M.C. King (Berkeley)

1. Kitzis. A. et al. Nature 333, 215 (1988).

Ien Kate, L.P., Te Meerman. G.J.. Buys, C.H.C.M. Halley. D.J.J. \& Oostra. B. Nature 334, 20 (1988).

Tümmler. B., Aschendorf. A.. Darnedde, T. \& Hundrieer. J. Nature 334, $110(1988)$

Estivill. X etal. Nature 326, 840-845 (1987)

Estivill. X et al. Genomics 1, 257-263 (1987)

Wainwright. B.J. et al. Nature 318, 384-385 (1985).

7. White. R. et al. Nature 318,382-384 (1985)

\section{Insect eating in Japan}

SiR-In response to John Treherne's review of Vincent Holt's book Why Not Eat Insects? (Nature 335, 126; 1988), I wish to provide some information on insectivory in Japan.

In autumn, in agricultural villages, rice hoppers (inago) are collected from the 